\title{
Analysing for 4,4'-diaminodiphenylmethane in heritage collections containing solid and medium density flexible linear polyester polyurethanes using liquid chromatography/ mass spectrometry
}

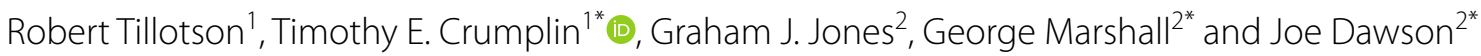

\begin{abstract}
Polyurethane (PUR) shoe soles from collections held by the Alfred Gillett Trust, stored for up to 50 years, were analysed for the presence of 4,4'-diaminodiphenylmethane (4,4'-MDA) - a substance of very high concern in Europe and classified as a carcinogen in USA. A review of the literature revealed no papers on long term room-temperature hydrolysis of urethane or urea linkages leading to the spontaneous formation of 4,4'-MDA in polyester or polyether polyurethanes made from 4,4'-diisocyanatodiphenylmethane (MDI). However, evidence emerged of its potential formation and a possible handling hazard was consequently identified in the heritage collection. By chemical analysis, shortcomings in the current literature could be addressed. Calibration of liquid chromatography-mass spectrometry equipment showed analysis of 4,4'-MDA was possible down to 1 ppm with an error of $2.5 \mathrm{ppm}$. No 4,4'-MDA was found in the PUR analyte solutions at a concentration $>1 \mathrm{ppm}$. Under these experimental parameters the samples were shown to comply with the industrially accepted CertiPUR 2017 standard for commercial slab-stock foams. Furthermore, no 4,4'-MDA was found in solution after an 'accelerated anaerobic hydrolysis test' on the sole materials. This test was designed and developed to assess the likelihood of future formation of the aromatic amine via a hydrolysis-only mechanism/s. Finally, $4,4^{\prime}$-MDA itself was heated in air at $70^{\circ} \mathrm{C}$ under 'humid' conditions to examine its stability. In this experiment the $4,4^{\prime}$ MDA altered in appearance and was reduced to ca $30 \%$ of its original weight. Subject to more work, it is conceivable 4,4'-MDA could be formed by hydrolysis, but degraded over time, and not detected in these tests.
\end{abstract}

Keywords: 4,4'-Diaminodiphenylmethane, MDI, Polyester, Polyurethane, Hydrolysis, Liquid chromatography/mass spectrometry, CertiPUR 2017

\section{The evidence for potential production of 4,4'-diaminodiphenylmethane}

Degradation of PUR artefacts is emerging as a salient theme for collections professionals in heritage

\footnotetext{
*Correspondence: tim.crumplin@agtrust.org.uk;

george.marshall@nottingham.ac.uk; joe.dawson@nottingham.ac.uk

${ }^{1}$ Alfred Gillett Trust, The Grange, Farm Road, Street, Somerset BA16 OBQ, UK

${ }^{2}$ The Business Partnership Unit, School of Chemistry, University of Nottingham, Nottingham NG7 2RD, UK
}

institutions [1]. Problems with degraded PUR soled shoes have been reported [2] and commercially available PUR shoe soling from diverse and largely unknown manufacturers and PUR material suppliers was chosen by the Alfred Gillett Trust (AGT) as a model substance for this investigation. Historically, PUR soles have been manufactured using either polyester (ES) or polyether (ET) polyols with "Pure MDI" [3, 4]. Spontaneous hydrolysis of PUR(ES) by atmospheric moisture and/or microorganisms has been reviewed [5]. Ether groups in PUR(ET) are shown to be stable to hydrolysis [6]. Literature on 
hydrolysis of PUR(ES) concentrates on degradation of the base polyol components and loss of physical performance. Little information exists on the potential production of $4,4^{\prime}$-MDA by scission of the urethane and urea linkages by natural hydrolysis. A priori, the influence of pigment and dye colourants might affect the stability of the urethane or urea linkages.

In the USA 4,4'-MDA appears in the NIOSH Occupational Cancer List [7] (synonyms: 4,4'-methylenedianiline, MDA). It is a substance of very high concern (SVHC) in Europe [9]. In the UK, the HSE [8, 15] imposes limits on employee exposure to $4,4^{\prime}$-MDA in the spraying of rigid PUR foams, because it is a known cause of contact dermatitis $[10,11] .4,4^{\prime}-\mathrm{MDA}$ is a product in the recovery processes from scrap PUR [12]. Stability to hydrolysis of the urethane link in polyether polyurethanes at elevated temperature has been reported [13]. Production of small amounts of 4,4'-MDA by the hydrolysis of PUR made from polycarbonate-based polyols was studied for in vivo applications [16]. For furniture applications using MDI in the production of slab stock foam, a voluntary manufacturers specification of $\leq 5 \mathrm{ppm}$ for $4,4^{\prime}$-MDA within the foam structure is given in CertiPUR 2017 [17] and the analytical method published therein was adapted to use samples of 0.5 to $5 \mathrm{~g}$.

Pellizzi et al. [14] reported the formation of TDA (2,4-diaminotoluene) in naturally degraded PUR objects made with TDI formulations, and 4,4'-MDA formation could be expected in chemically analogous MDI formulations.

\section{LCMS analysis}

A commercial sample of 4,4'-MDA (Sigma Aldrich, > 97\%, $\mathrm{GC}$ ) was obtained to construct a calibration curve in the range 0-100 ppm using LCMS methods. A 4,4'-MDA solution in $1 \%$ aqueous acetic acid was used in this process, made by serial dilution of a $1000 \mathrm{ppm}$ stock solution using volumetric methods. The extracted ion chromatogram (EIC) obtained by mass spectrometry was then used to construct new calibration graphs in the range $0 \mathrm{ppm}$ to $10 \mathrm{ppm}$. The limit of detection of this method was determined to be $<1 \mathrm{ppm}$. To account for variances in the LCMS system over time, this calibration process was repeated for each of 4 batches of PUR samples supplied over several months (Fig. 1).

Thirty PUR soles were selected from a range of manufacturers spanning 1970 to 1999 . The analysis samples were sourced from the interior of the sole portion to avoid contamination by surface impurities which could distort the analysis results. The analysis liquors were prepared by mixing each cut sample independently with aqueous $1 \%$ acetic acid at a 1:5 weight/weight ratio in an ultrasonic bath for $2 \mathrm{~h}$. To eliminate possible error at this very low-level detection $(<1 \mathrm{ppm})$, after each sample LCMS run a supplementary LCMS quality control run was performed. The original

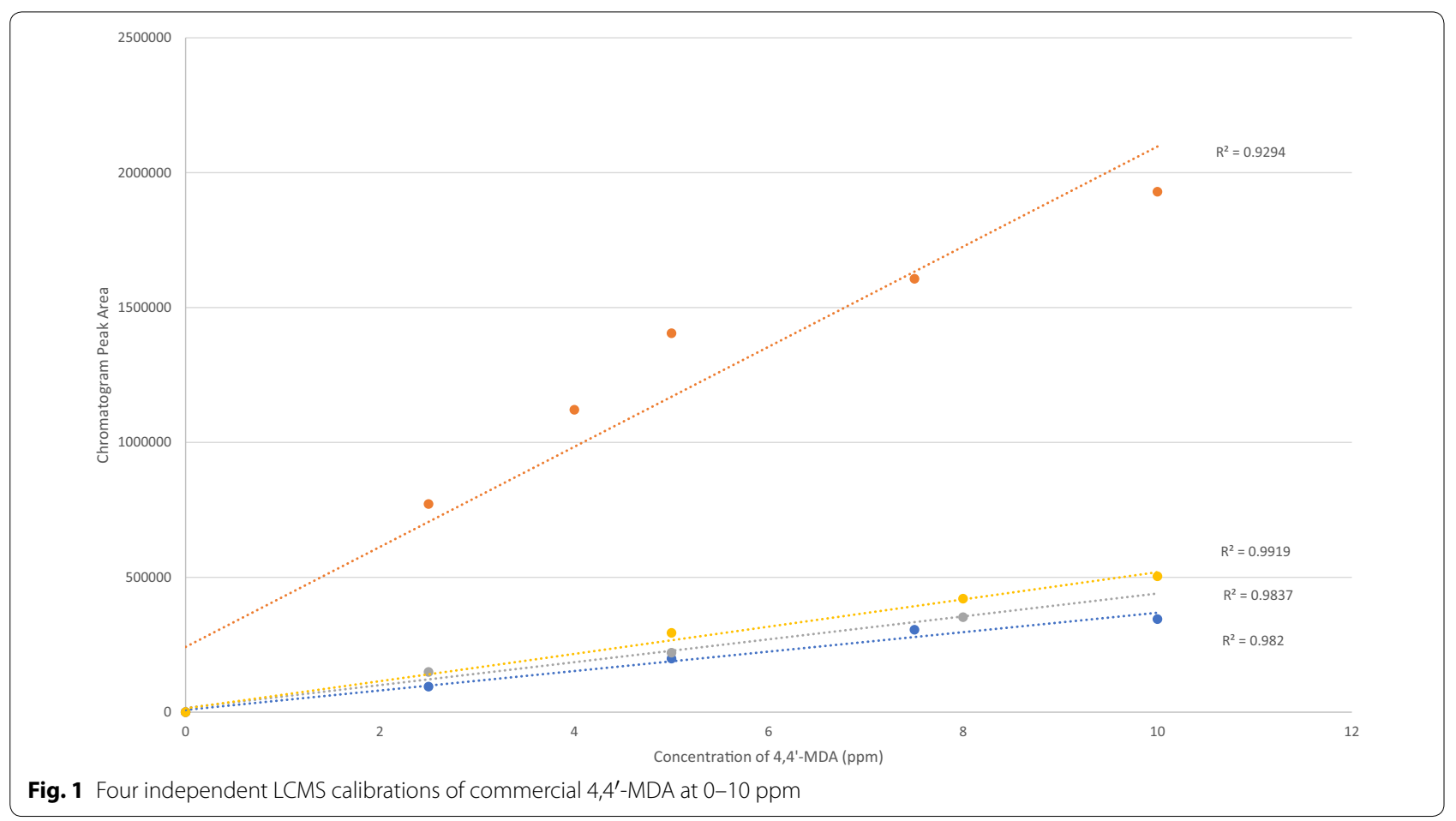


Table 1 Normal and spiked LCMS results obtained from naturally hydrolysed polyurethane shoe soles stored for up to 50 years

\begin{tabular}{|c|c|c|c|c|c|c|c|c|}
\hline \multirow[t]{2}{*}{$\begin{array}{l}\text { Sample } \\
\text { number }\end{array}$} & \multirow[t]{2}{*}{$\begin{array}{l}\text { Approx. date } \\
\text { of manufacture }\end{array}$} & \multirow{2}{*}{$\begin{array}{l}\text { AGT Sample } \\
\text { identification } \\
\text { code }\end{array}$} & \multirow[t]{2}{*}{$\begin{array}{l}\text { PUR sample } \\
\text { construction }\end{array}$} & \multirow[t]{2}{*}{$\begin{array}{l}\text { PUR sample } \\
\text { colour }\end{array}$} & \multicolumn{2}{|c|}{$\begin{array}{l}\text { Normal LCMS solution } \\
\text { results }\end{array}$} & \multicolumn{2}{|c|}{$\begin{array}{l}\text { Spiked LCMS solution } \\
\text { results }\end{array}$} \\
\hline & & & & & $\begin{array}{l}\text { Chromatogram } \\
\text { peak area }\end{array}$ & $\begin{array}{l}\text { ppm } \\
\text { in PUR } \\
\text { sample }\end{array}$ & $\begin{array}{l}\text { Chromatogram } \\
\text { peak area }\end{array}$ & $\begin{array}{l}\text { ppm } \\
\text { in PUR } \\
\text { sample }\end{array}$ \\
\hline 1 & 1970 & M19+SD118 & Single density & Black & 0 & 0 & 256,000 & 4.8 \\
\hline 2 & 1974 & $1234 / 2926$ & Single density & Dark brown & 0 & 0 & 217,000 & 3.9 \\
\hline 3 & 1972 & M19+SD100 & Single density & Tan & 0 & 0 & 200,000 & 3.6 \\
\hline 4 & 1970 & M19+SD122 & Single density. & Black & 0 & 0 & 162,000 & 2.9 \\
\hline 5 & 1971 & 1234/1918A & Single density & Black & 0 & 0 & 201,000 & 3.7 \\
\hline 6 & 1970 & $1974 / 770$ & Single density & Black & 0 & 0 & 206,000 & 3.8 \\
\hline 7 & 1977 & $1234 / 3115$ & $\begin{array}{l}\text { Single density } \\
\text { solid elastomer }\end{array}$ & Tan-orange & 0 & 0 & 211,000 & 3.9 \\
\hline 8 & 1970 & M19+SD123 & Single density & Black & 0 & 0 & 203,000 & 3.8 \\
\hline 9 & 1975 & $1234 / 2934$ & Single density & Beige-mid-brown & 0 & 0 & 169,000 & 3.1 \\
\hline 10 & 1975 & $1234 / 2933$ & Single density & Mid-brown & 0 & 0 & 183,000 & 3.4 \\
\hline 11 & 1974 & $1234 / 2889$ & Single density & Black & 0 & 0 & 194,000 & 3.5 \\
\hline 12 & 1973 & $1234 / 2864$ & Single density & Tan-orange & 0 & 0 & 181,000 & 3.3 \\
\hline 13 & 1975 & W19/SD865 & Single density & Beige-mid-brown & 0 & 0 & 197,000 & 3.6 \\
\hline 14 & 1973 & $1234 / 2865 B$ & Single density & Mid-brown & 0 & 0 & 190,000 & 3.5 \\
\hline 15 & 1981 & M19/SD339 & $\begin{array}{l}\text { Dual density } \\
\text { Outsole }\end{array}$ & Tan- orange & 0 & 0 & 105,000 & 2.6 \\
\hline 16 & 1981 & M19/SD339 & $\begin{array}{l}\text { Dual density. Mid- } \\
\text { sole }\end{array}$ & Black & 0 & 0 & 119,000 & 3.1 \\
\hline 17 & 1989 & C19+SD614 & $\begin{array}{l}\text { Dual density. } \\
\text { Midsole }\end{array}$ & Off-white & 10,200 & 0.3 & 98,700 & 2.5 \\
\hline 18 & 1985 & C19+SD458LA & Single density & Light grey & 0 & 0 & 119,000 & 3.0 \\
\hline 19 & 1997 & Sundapple & Single density & White & 0 & 0 & 102,000 & 2.6 \\
\hline 20 & 1996 & 0161 & $\begin{array}{l}\text { Dual density. } \\
\text { Outsole }\end{array}$ & Black & 11,800 & 0.3 & 189,000 & 4.5 \\
\hline 21 & 1996 & 0161 & $\begin{array}{l}\text { Dual density. } \\
\text { Midsole }\end{array}$ & Grey & 0 & 0 & 138,000 & 3.5 \\
\hline 22 & 1982 & W19+SD132 & Single density & Tan & 0 & 0 & 135,000 & 3.4 \\
\hline 23 & 1980-1999 & $\mathrm{SHO} / 5 / 23 / 3$ & Single density & Cream & 0 & 0.00 & 778,000 & 2.7 \\
\hline 24 & 1980-1999 & $\mathrm{SHO} / 5 / 8 / 1$ & Single density & Cream & 0 & 0.00 & 776,000 & 2.7 \\
\hline 25 & 1980-1999 & $C R / 361 / 17$ & Single density & Brown & 24,700 & 0.02 & 342,000 & 1.2 \\
\hline 26 & 1980-1999 & $\mathrm{SHO} / 5 / 37 / 1$ & Single density & Cream & 27,800 & 0.02 & 419,000 & 1.4 \\
\hline 27 & 1980-1999 & $\mathrm{SHO} / 5 / 5 / 2$ & Single density & Cream & 0 & 0.00 & 768,000 & 2.7 \\
\hline 28 & 1980-1999 & $\mathrm{SHO} / 5 / 155$ & Single density & Cream-brown & 23,100 & 0.02 & 333,000 & 1.1 \\
\hline 29 & 1982 & W19/SD1322 & $\begin{array}{l}\text { Single density. } \\
\text { High blow } \\
\text { (hydrolysed } \\
4 \text { weeks) }\end{array}$ & $\operatorname{Tan}$ & 0 & 0.00 & 149,000 & 3.0 \\
\hline 30 & 1982 & W19/SD1322 & $\begin{array}{l}\text { Single density. } \\
\text { High blow } \\
\text { (hydrolysed } \\
8 \text { weeks) }\end{array}$ & Tan & 0 & 0.00 & 757,000 & 2.6 \\
\hline
\end{tabular}

All samples were coloured by pigments or dyestuffs and showed appreciable physical degradation. Results for accelerated hydrolysis tests are shown in Sample numbers 29 and 30

shoe sample liquor was 'spiked' with an additional $5 \mathrm{ppm}$ of $4,4^{\prime}$-MDA by adding a $10 \mathrm{ppm} 4,4^{\prime}$-MDA in $1 \%$ acetic acid solution in 50/50 ratio to the original shoe sample liquor. The 4,4'-MDA level in the sample can be determined by subtracting $5 \mathrm{ppm}$ from the measured LCMS value in the spiked sample. This spiking methodology allows the performance of the analytical method to be validated by ensuring that the amount of $4,4^{\prime}-\mathrm{MDA}$ added is equal to that 
Table 2 Normal and spiked LCMS results obtained from accelerated ageing of commercial grade 4,4'-MDA

\begin{tabular}{|c|c|c|c|c|}
\hline & \multicolumn{2}{|c|}{$\begin{array}{l}\text { Normal LCMS solution } \\
\text { results }\end{array}$} & \multicolumn{2}{|c|}{$\begin{array}{l}\text { Spiked LCMS solution } \\
\text { results }\end{array}$} \\
\hline & $\begin{array}{l}\text { Chromato- } \\
\text { gram peak } \\
\text { area }\end{array}$ & $\begin{array}{l}\text { ppm in PUR } \\
\text { sample }\end{array}$ & $\begin{array}{l}\text { Chromato- } \\
\text { gram peak } \\
\text { area }\end{array}$ & $\begin{array}{l}\text { ppm in PUR } \\
\text { sample }\end{array}$ \\
\hline $\begin{array}{l}\text { Aged } 4,4^{\prime}- \\
\text { MDA }\end{array}$ & 469,000 & 1.6 & $1,370,000$ & 4.9 \\
\hline
\end{tabular}

analytically observed. Importantly, correlation between the un-spiked and 'corrected value' for the spiked samples validates our data (Table 1).

The results of the LCMS analysis of the shoe liquors of naturally hydrolysed and spiked samples are shown in Table 1. No. 4,4' MDA was detected above $0.3 \mathrm{ppm}$ (within an error of ca. $2.5 \mathrm{ppm}$ ) under these experimental conditions.

\section{Accelerated hydrolysis tests}

It is conceivable $4,4^{\prime}$-MDA would be produced by spontaneous hydrolysis in future years [13]. To intentionally accelerate hydrolysis of the urethane and urea links in a PUR foam, ca $0.4 \mathrm{~g}$ to $0.5 \mathrm{~g}$ of two highly blown PUR samples were suspended over deionised water in sealed pressure tubes and held at $70{ }^{\circ} \mathrm{C}$ for 4 weeks and 8 weeks respectively. The highly blown PUR formulations contain larger proportions of MDI and could be more likely to produce $4,4^{\prime}$-MDA. The residues were analysed by LCMS in a similar way to that described in the LCMS analysis section above (Table 1, Sample numbers 29 and 30).

\section{Accelerated atmospheric ageing effects on commercial grade $4,4^{\prime}$-MDA chemical (97\% purity)}

A vial containing $22.1 \mathrm{mg}$ of commercial 4,4'-MDA was suspended in a flask over a deionised water reservoir. The flask was open to the atmosphere and held at $70^{\circ} \mathrm{C}$ for 4 weeks with a condenser attached to prevent loss of water. After analysis of the resultant sample by LCMS, only ca. $30 \%$ of the original $4,4^{\prime}$-MDA remained in the "aged" acetic acid solution compared to a recently prepared 5 ppm solution (Table 2). The aged 4,4'-MDA left a yellow insoluble deposit indicating decomposition.

\section{Conclusions}

In naturally hydrolysed and accelerated hydrolysed PUR(ES) no 4,4'-MDA was detected in the resultant liquor under these experimental conditions, even in physically degraded sole samples. The maximum
$4,4^{\prime}$-MDA concentration recorded was $0.3 \mathrm{ppm}$, indicating the level of $4,4^{\prime}-\mathrm{MDA}$ in $\operatorname{PUR}(\mathrm{ES})$ is $\leq 5 \mathrm{ppm}$ under these experimental conditions and below the CertiPUR 2017 [16] limit for PUR foams. The colour of the PUR had no observable influence on hydrolysis under these conditions. The method used was developed in the absence of a procedure to analyse heritage objects containing polyurethane for the existence of $4,4^{\prime}$-MDA, and confirmed that heritage collection items in this instance are safe to handle for the foreseeable future. In moist aerobic conditions, 4,4'-MDA degrades at $70{ }^{\circ} \mathrm{C}$ through an as-yet undetermined mechanism. Conceivably 4,4'-MDA might be formed by hydrolysis of the urethane or urea linkages degrading over time but not able to be detected in this work, using these experimental conditions. Further investigation is required for confirmation, or otherwise, to monitor long-term levels of 4,4-MDA produced by polyurethane held in heritage collections.

\section{Abbreviations \\ AGT: Alfred Gillett Trust; EIC: extracted ion chromatogram; ES: ester; ET: ether GC: gas chromatography; HSE: Health and Safety Executive; LCMS: Liquid chromatography-mass spectrometry; MDI: 4,4'-diisocyanatodiphenylmeth- ane; ppm: parts per million; PUR: polyurethane; TDA: 2,4-diaminotoluene; TDI: 2,4-toluenediisocyanate; UoN: University of Nottingham; SVHC: substance of very high concern; 4,4'-MDA, MDA: 4,4'-diaminodiphenylmethane, 4,4'-methylenedianiline.}

\section{Acknowledgements \\ The Alfred Gillett Trust initiated this research.}

\section{Authors' contributions}

RT drafted the manuscript and designed the testing programme. TEC provided samples from the heritage collection at AGT. GM and JD developed the LCMS analytical technique, oversaw sample preparation, analysis work and interpreted the results. GJJ undertook the LCMS analytical work. All authors read and approved the final manuscript.

Funding

Not applicable.

\section{Availability of data and materials}

The data sets generated and/or analysed during the current study are not publicly available due to ownership by a private collection but are available from the corresponding author on reasonable request.

\section{Competing interests}

This research has been carried out without any commercial or financial relationships that might knowingly involve any competing interests.

Received: 9 April 2019 Accepted: 29 June 2019

Published online: 13 July 2019

References

1. Popart. Preservation of Plastic ARTefacts in museum collections. http:// popart-highlights.mnhn.fr/index.html and http://popart-highlights .mnhn.fr/wp-content/uploads/2_Identification/1_What_plastics_are_ in_my_collection/2_2_NeedForAPlasticReferenceSampleCollection.pdf. Accessed 08 Aug 2018. 
2. The Sneakerheads racing to save their kicks from decay. https://www. wired.com/2015/05/sneakers/. Accessed 08 Aug 2018.

3. Saunders $\mathrm{JH}$, Frisch $\mathrm{KH}$. Polyurethane chemistry and technology. New York: Interscience; 1962. p. 73.

4. Limerkens N. The Huntsman polyurethanes book. In: Randall D, Lee SA, editors. New York: Wiley; 2002.

5. Nakajima-Kambe T, Shigeno-Akutsu Y, Nomura N, Onuma F, Nakahara T. Microbial degradation of polyurethane, polyester polyurethanes and polyether polyurethanes. Appl Microbiol Biotechnol. 1999:51:134-40.

6. Le Gac PY, Choqueuse D, Melot D. Description and modelling of polyurethane hydrolysis used as thermal insulation in oil offshore conditions. Polym Testing. 2013;32(8):1588-93. https://doi.org/10.1016/j.polymertes ting.2013.10.009.

7. The National Institute for Occupational Safety and Health (NIOSH). Occupational Cancer. Carcinogen List. http://www.cdc.gov/niosh/topics/ cancer/npotocca.html\#d. Accessed 08 Aug 2018.

8. EH40/2005 Workplace exposure limits. Containing the list of workplace exposure limits for use with the Control of Substances Hazardous to Health Regulations (as amended). http://www.hse.gov.uk/pubns/priced/ eh40.pdf. Accessed 08 Aug 2018.

9. Member state committee support document for identification of 4,4'-diaminodiphenylmethane (MDA) as a substance of very high concern. https://echa.europa.eu/documents/10162/d36424e7-b12d-4dd8832e-6d7e3e283fc3. Accessed 08 Aug 2018.

10. Liippo J, Lammintausta K. Contact sensitization to 4,4'-diaminodiphenylmethane and to isocyanates among general dermatology patients. Contact Dermatitis. 2008;59:109-14.

11. Kieć-Świerczyńska M, Świerczyńska-Machura D, Chomiczewska-Skóra D, Nowakowska-Świrta E, Kręcisz B. Occupational allergic and irritant contact dermatitis in workers exposed to polyurethane foam. Int J Occup Med Environ Health. 2014;27(2):196-205. https://doi.org/10.2478/s1338 2-014-0249-9.

12. Behrendt G, Naber BW. The chemical recycling of polyurethanes (Review). J Univ Chem Technol Metallurgy. 2009;44(1):3-23.

13. Chaffin KA, Xiangji C, McNamara L, Bates FS, Marc A, Hillmeyer MA. Polyether urethane hydrolytic stability after exposure to deoxygenated water. Macromolecules. 2014;47:5220-6.

14. Pellizzi $\mathrm{E}$, Lattatui-Derieux $\mathrm{A}$, Lavédrine $\mathrm{B}$, Cheradame $\mathrm{H}$. Degradation of polyurethane ester foam artifacts: chemical properties, mechanical properties and comparison between accelerated and natural degradation. Polym Degrad Stab. 2014;107:255-61.

15. Health and Safety Laboratory. Methods for the determination of Hazardous Substances, MDHS75/2. Aromatic amines in air and on surfaces. http://www.hse.gov.uk/pubns/mdhs/pdfs/mdhs75-2.pdf. Accessed 08 Aug 2018.

16. Yang YW, Labow RS, Santerre JP. Isolation of methylene dianiline and aqueous-soluble biodegradation products from polycarbonate-polyurethanes. Biomaterials. 2003;24:2805-19.

17. European Association of Flexible Polyurethane Foam Blocks Manufacturers. CertiPUR Label for flexible polyurethane foams, application form and technical requirements. Section III. Technical requirements. Subsection 1.3; 2017. http://www.europur.org/images/CertiPUR_Techn ical_Paper___Full_Version_-_2017.pdf. Accessed 08 Aug 2018.

\section{Publisher's Note}

Springer Nature remains neutral with regard to jurisdictional claims in published maps and institutional affiliations.

\section{Submit your manuscript to a SpringerOpen ${ }^{\circ}$ journal and benefit from:}

- Convenient online submission

- Rigorous peer review

- Open access: articles freely available online

- High visibility within the field

- Retaining the copyright to your article

Submit your next manuscript at springeropen.com 